TITLE:

\title{
Phase Diagram Investigations of the Bi-Ti System
}

$\operatorname{AUTHOR}(S)$ :

Maruyama, Sho; Kado, Yuya; Uda, Tetsuya

\section{CITATION:}

Maruyama, Sho ...[et al]. Phase Diagram Investigations of the Bi-Ti System. Journal of Phase Equilibria and Diffusion 2013, 34(4): 289-296

ISSUE DATE:

2013-08

URL:

http://hdl.handle.net/2433/191004

\section{RIGHT:}

This paper was published in Journal of Phase Equilibria and Diffusion, Vol.34, Issue 4, pp. 289-296 and is made available as an electronic reprint with the permission of ASM International. One print or electronic copy may be made for personal use only. Systematic or multiple reproduction, distribution to multiple locations via electronic or other means, duplications of any material in this paper for a fee or for commercial purposes, or modification of the content of this paper are prohibited. 


\title{
Phase Diagram Investigations of the Bi-Ti System
}

\author{
Sho Maruyama, Yuya Kado, and Tetsuya Uda
}

(Submitted March 26, 2013; published online May 7, 2013)

\begin{abstract}
The liquidus and invariant reaction temperatures were measured by thermal analyses for $\mathrm{Bi}-\mathrm{T} \mathrm{i}$ alloys containing 0-65 at.\% of $\mathrm{Ti}$. The liquidus temperatures were clearly much lower than the literature values. Equilibrium experiments showed the existence of a new phase, $\mathrm{Bi}_{2} \mathrm{Ti}_{3}$. However, the reported $\mathrm{Bi}_{3} \mathrm{Ti}_{2}$ phase was not observed in the present study. The temperatures of the peritectic reaction involving $\mathrm{Bi}_{2} \mathrm{Ti}, \mathrm{Bi}_{9} \mathrm{Ti}_{8}$, and $\mathrm{Bi}_{2} \mathrm{Ti}_{3}$ were also clarified to be 425,930 , and $970{ }^{\circ} \mathrm{C}$, respectively. Thus, a new phase diagram of the Bi-Ti system was constructed.
\end{abstract}

Keywords Bi-Ti system, liquidus temperature, phase diagram

\section{Introduction}

Many efforts to construct the phase diagram of the Bi-Ti system have been made by several researchers. ${ }^{[1-8]}$ The Bi-Ti phase diagram was drawn by Murray in $1994,{ }^{[1]}$ but only two intermetallic compounds, $\mathrm{BiTi}_{2}$ and $\mathrm{BiTi}_{3}$, were known at that time along with their crystal structures. ${ }^{[2,3]}$ This phase diagram was adopted by Massalski in $1996 .{ }^{[4]}$ In 1997, Richter and Jeitschko ${ }^{[5]}$ reported a new compound $\mathrm{Bi}_{9} \mathrm{Ti}_{8}$ as well as its crystal structure. Furthermore, in 2006, Vassilev ${ }^{[6]}$ discovered new three phases, $\mathrm{Bi}_{2} \mathrm{Ti}, \mathrm{Bi}_{3} \mathrm{Ti}_{2}$, and BiTi by a solid/liquid diffusion couple method in quartz tubes at 400 to $700{ }^{\circ} \mathrm{C}$, although the BiTi phase was considered to be identical with the previously reported $\mathrm{Bi}_{9} \mathrm{Ti}_{8}$. In 2010, considering all these reports, Okamoto ${ }^{[7]}$ proposed the $\mathrm{Bi}-\mathrm{Ti}$ phase diagram where $\mathrm{Bi}_{9} \mathrm{Ti}_{8}$ was chosen instead of BiTi. However, the liquidus and invariant reaction temperatures, particularly in the bismuth-rich region, were determined tentatively without detailed investigations. Only Weeks ${ }^{[8]}$ studied the bismuth-rich region (less than 5 at.\% of Ti) at 300 to $700{ }^{\circ} \mathrm{C}$ by annealing $\mathrm{Bi}$ in $\mathrm{Ti}$ crucibles or mixing $\mathrm{Bi}$ and $\mathrm{Ti}$ in $\mathrm{Fe}$ or $\mathrm{Cr}$ crucibles. No other work on the liquidus in the bismuth-rich region has been done.

In the present study, we determined the liquidus and invariant reaction temperatures of $\mathrm{Bi}-\mathrm{Ti}$ alloys (0-65 at.\% of Ti) by thermal analyses. Equilibrium experiments were also carried out to explore the intermetallic compounds and invariant reactions.

Sho Maruyama, Yuya Kado, and Tetsuya Uda, Department of Materials Science and Engineering, Graduate School of Engineering, Kyoto University, Yoshida-honmachi, Sakyo-ku, Kyoto 606-8501, Japan. Contact e-mails: materials_process@aqua.mtl.kyoto-u.ac.jp; uda.tetsuya.5e@kyoto-u.ac.jp.

\section{Experimental}

Bismuth (99.999\%, supplied by Kamioka Mining \& Smelting Co. Ltd.) and sponge titanium ( $>99 \%$, Wako Pure Chemical Industries, Ltd.) were mixed with certain compositions as summarized with the results in Table 1. These mixtures in $\mathrm{MgO}$ crucibles were placed in a stainless steel container in a glove box filled with Ar gas and a lid was put on. The container was moved to atmosphere and sealed by TIG welding. In order to make homogeneous alloys, prethermal treatments were performed at $1000{ }^{\circ} \mathrm{C}$ (for the alloy containing $0-40$ at. $\%$ of Ti) or $1200{ }^{\circ} \mathrm{C}$ (for the alloy containing $45-65$ at.\% of Ti). After $40 \mathrm{~h}$, the alloys were quenched in water at room temperature. The alloys were heated again in a $\mathrm{MgO}$ crucible. The crucible was placed in another stainless steel container and a lid with a hole was welded. The thermocouple with a $\mathrm{MgO}$ protector tube was inserted through the hole to measure the temperatures in the alloys. Figure 1 shows a schematic illustration of the apparatus. The stainless steel containers were heated and held at $1000-1200{ }^{\circ} \mathrm{C}$ for over $3 \mathrm{~h}$ in an Inconel or alumina vessel filled with Ar gas. Then, the furnace was turned off and the temperature of the alloy was monitored during cooling. After cooling to room temperature, some alloys were used for heating curve measurements.

The Bi-Ti alloys containing 30,40, 50, and 65 at.\% of Ti in the $\mathrm{MgO}$ crucible in the closed stainless steel container were employed for equilibrium experiments, the conditions of which are summarized in Table 2. Except for Exp. \#1, the mixtures of $\mathrm{Bi}$ and $\mathrm{Ti}$ were held at higher temperatures than their liquidus temperatures (established in this study) for $40 \mathrm{~h}$ to make homogeneous alloys in advance. Afterward, the stainless steel containers were cooled in the furnace to the holding temperatures as shown in Table 2. They were held for several tens of hours and then quenched in water.

The phases in the alloy were identified by an $\mathrm{x}$-ray diffractometer (XRD, CuK $\alpha, X^{\prime}$ 'pert Pro, PANalytical, Almelo). The compositions of $\mathrm{Bi}$ and $\mathrm{Ti}$ were determined by energy dispersive $\mathrm{x}$-ray spectroscopy (EDX, EDAX VE-9800), using a scanning electron microscope (SEM, KEYENCE VE-7800), and inductively coupled plasma atomic emission spectrometry (ICP-AES, SII SPS3500). The EDX results were calibrated on the basis of the results by ICP analysis. 
Table 1 Temperatures of the liquidus and invariant reactions of the Bi-Ti alloys determined by heating and cooling curve measurements

\begin{tabular}{|c|c|c|c|c|c|c|}
\hline \multirow[b]{2}{*}{ Bi:Ti, at.\% } & \multicolumn{4}{|c|}{ Cooling curve, ${ }^{\circ} \mathrm{C}$} & \multicolumn{2}{|c|}{ Heating curve, ${ }^{\circ} \mathrm{C}$} \\
\hline & Liquidus temp. & Invariant reaction I & Invariant reaction III & Invariant reaction IV & Invariant reaction I & Invariant reaction II \\
\hline $100: 0$ & $\cdots$ & 268 & $\cdots$ & $\cdots$ & 271 & $\ldots$ \\
\hline $95: 5$ & 710 & 266 & $\cdots$ & $\cdots$ & 255 & 425 \\
\hline $90: 10$ & 790 & 264 & $\ldots$ & $\ldots$ & 249 & 417 \\
\hline $85: 15$ & 837 & 265 & $\cdots$ & $\cdots$ & 251 & 415 \\
\hline $80: 20$ & 864 & 265 & $\ldots$ & $\ldots$ & $\ldots$ & $\ldots$ \\
\hline $75: 25$ & 883 & 267 & $\ldots$ & $\ldots$ & 256 & 424 \\
\hline $70: 30$ & 895 & 262 & $\cdots$ & $\cdots$ & 252 & 418 \\
\hline $65: 35$ & 911 & 261 & $\ldots$ & $\ldots$ & $\ldots$ & $\ldots$ \\
\hline $60: 40$ & 940 & 259 & 925 & $\ldots$ & 254 & 423 \\
\hline $55: 45$ & 959 & 267 & 928 & $\ldots$ & $\ldots$ & $\ldots$ \\
\hline $50: 50$ & 972 & $\ldots$ & 940 & $\ldots$ & $\ldots$ & 422 \\
\hline $45: 55$ & 984 & $\ldots$ & 936 & $\ldots$ & $\ldots$ & $\ldots$ \\
\hline $40: 60$ & 1053 & $\ldots$ & $\ldots$ & 967 & $\ldots$ & $\ldots$ \\
\hline $35: 65$ & 1123 & $\ldots$ & $\ldots$ & 972 & $\ldots$ & $\ldots$ \\
\hline
\end{tabular}

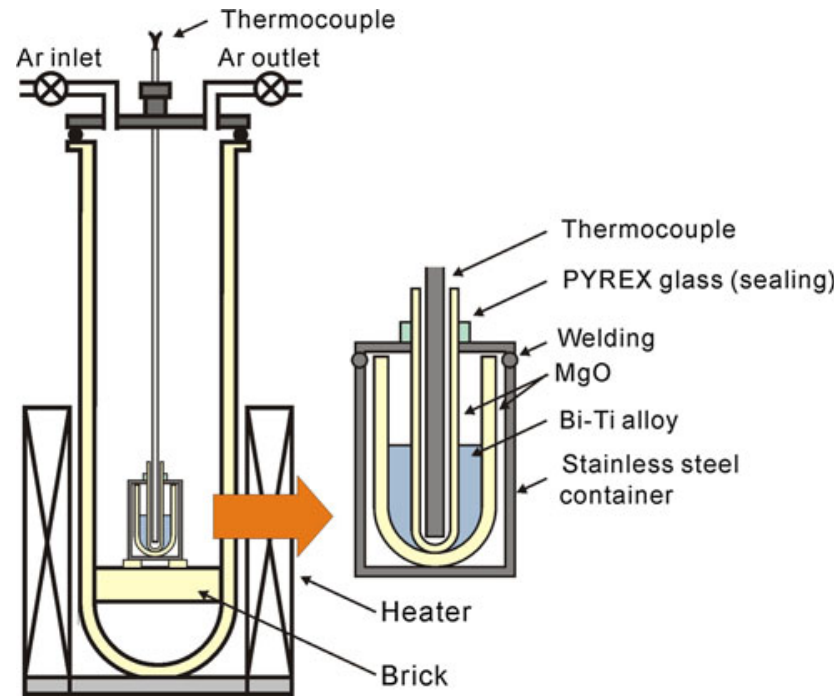

Fig. 1 Schematic illustration of the apparatus for cooling and heating curve measurements

\section{Results and Discussion}

\subsection{Cooling and Heating Curve Measurements}

Figure 2 shows the temperature and the time derivative of temperature $(d T / d t)$ acquired by (a) cooling and (b) heating curve measurements of the alloy containing 40 at.\% of Ti. Four perturbations on cooling and heating curves were observed. The onset temperatures of the perturbations were taken as the temperatures of the liquidus or invariant reactions. It is considered that the perturbation at $940{ }^{\circ} \mathrm{C}$ in the cooling curve measurement is related to the reaction at liquidus and others to the invariant reactions (I, II, and III). Figures 3 and 4 show the time derivative of temperature against temperature acquired by cooling and heating curve measurements of the alloys with other compositions, and the temperatures of liquidus and invariant reactions were determined as summarized in Table 1. Four types of invariant reactions (I-IV) were observed. The temperatures of liquidus and invariant reactions were plotted on the phase diagram reported by Okamoto in Fig. 5. In the figure, open symbols denote the results from the cooling curve and the closed symbols are the results from the heating curve. Determined temperatures of liquidus and invariant reaction are indicated by arrows. Most remarkable is that the liquidus temperatures are much lower than the reported values. ${ }^{[8]}$ In addition, the temperatures of the invariant reactions II, III, and IV are significantly different from those in the previous phase diagram.

Reaction I is melting/solidification of $\mathrm{Bi}$. The melting point of pure $\mathrm{Bi}$ was determined to be $268{ }^{\circ} \mathrm{C}$, and this is in good agreement with the literature value $\left(271^{\circ} \mathrm{C}\right) .{ }^{[7]}$ This result means that the measurements were done successfully. The reason why our value is a little lower than the reported melting temperature of pure $\mathrm{Bi}$ may be because a eutectic reaction occurs. However, we cannot declare whether it is eutectic or peritectic since it may include some errors caused by supercooling or thermal gradient in the alloy. It is deduced from the reported phase diagram that reactions II and III are associated with peritectic reactions. The invariant reaction II was observed only by the heating curve measurement. This would be because the heating rate $\left(10^{\circ} \mathrm{C} / \mathrm{min}\right)$ was five times higher 
Table 2 Experimental conditions of equilibrium experiments and the compositions of each phase determined by EDX point analyses

\begin{tabular}{|c|c|c|c|c|c|c|c|c|c|}
\hline \multirow[b]{2}{*}{ Exp.\# } & \multirow[b]{2}{*}{ Bi:Ti, at.\% } & \multicolumn{2}{|c|}{ Homogenization } & \multicolumn{2}{|c|}{ Holding } & \multicolumn{4}{|c|}{ EDX result } \\
\hline & & Temp., ${ }^{\circ} \mathrm{C}$ & Time, h & Temp., ${ }^{\circ} \mathrm{C}$ & Time, h & Phase & $\mathrm{Bi}$, at. $\%$ & Ti, at. $\%$ & Conceivable compounds \\
\hline \multirow[t]{6}{*}{1} & $60: 40$ & $\cdots$ & $\cdots$ & 900 & 65 & A & 97.5 & 2.5 & Liquid \\
\hline & & & & & & $\mathrm{C}$ & 53.0 & 47.0 & $\mathrm{Bi}_{9} \mathrm{Ti}_{8}$ \\
\hline & & & & & & $\mathrm{D}$ & 40.4 & 59.6 & $\mathrm{Bi}_{2} \mathrm{Ti}_{3}$ \\
\hline & & & & & & $\mathrm{E}$ & 32.0 & 68.0 & $\mathrm{BiTi}_{2}$ \\
\hline & & & & & & $\mathrm{F}$ & 23.8 & 76.2 & $\mathrm{BiTi}_{3}$ \\
\hline & & & & & & $\mathrm{G}$ & 2.7 & 97.3 & (Ti) \\
\hline \multirow[t]{3}{*}{2} & $70: 30$ & 1000 & 40 & 420 & 45 & $\mathrm{~A}$ & 96.9 & 3.1 & Liquid \\
\hline & & & & & & $\mathrm{B}$ & 65.2 & 34.8 & $\mathrm{Bi}_{2} \mathrm{Ti}$ \\
\hline & & & & & & $\mathrm{C}$ & 51.5 & 48.5 & $\mathrm{Bi}_{9} \mathrm{Ti}_{8}$ \\
\hline \multirow[t]{2}{*}{3} & $70: 30$ & 1000 & 40 & 430 & 45 & A & 95.8 & 4.2 & Liquid \\
\hline & & & & & & $\mathrm{C}$ & 52.4 & 47.6 & $\mathrm{Bi}_{9} \mathrm{Ti}_{8}$ \\
\hline \multirow[t]{3}{*}{4} & $50: 50$ & 1150 & 40 & 850 & 265 & $\mathrm{C}$ & 54.9 & 45.1 & $\mathrm{Bi}_{9} \mathrm{Ti}_{8}$ \\
\hline & & & & & & $\mathrm{D}$ & 43.9 & 56.1 & $\mathrm{Bi}_{2} \mathrm{Ti}_{3}$ \\
\hline & & & & & & $\mathrm{E}$ & 35.0 & 65.0 & $\mathrm{BiTi}_{2}$ \\
\hline \multirow[t]{2}{*}{5} & $35: 65$ & 1200 & 40 & 950 & 95 & $\mathrm{D}$ & 39.3 & 60.7 & $\mathrm{Bi}_{2} \mathrm{Ti}_{3}$ \\
\hline & & & & & & $\mathrm{E}$ & 32.4 & 67.6 & $\mathrm{BiTi}_{2}$ \\
\hline
\end{tabular}
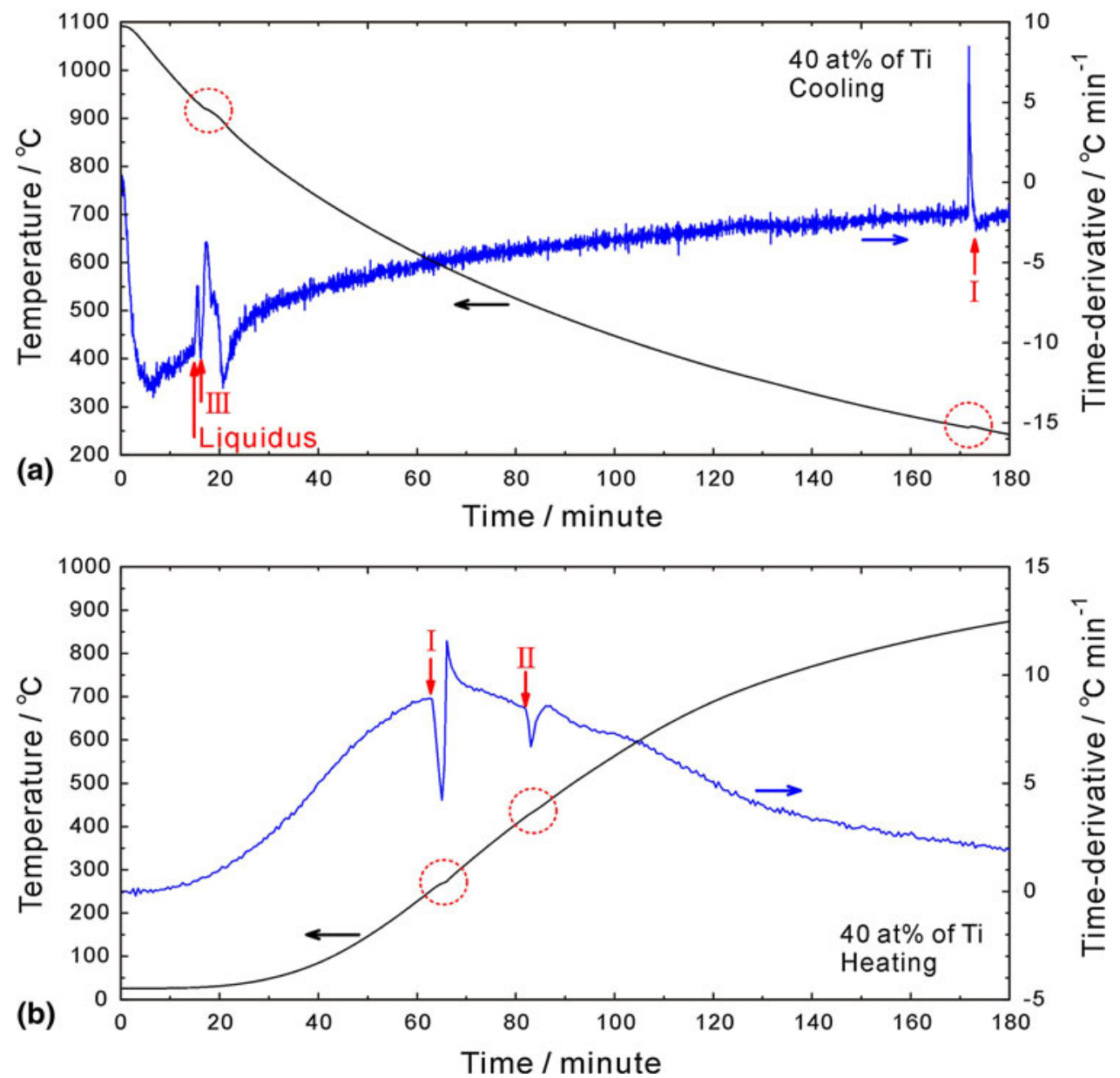

Fig. 2 Temperature and time derivative of temperature against time obtained by cooling curve measurements (a) and heating curve measurements (b) of the alloy containing 40 at.\% of Ti. The arrows indicate the beginnings of rapid changes in time derivative caused by the reaction at liquidus and invariant reactions 


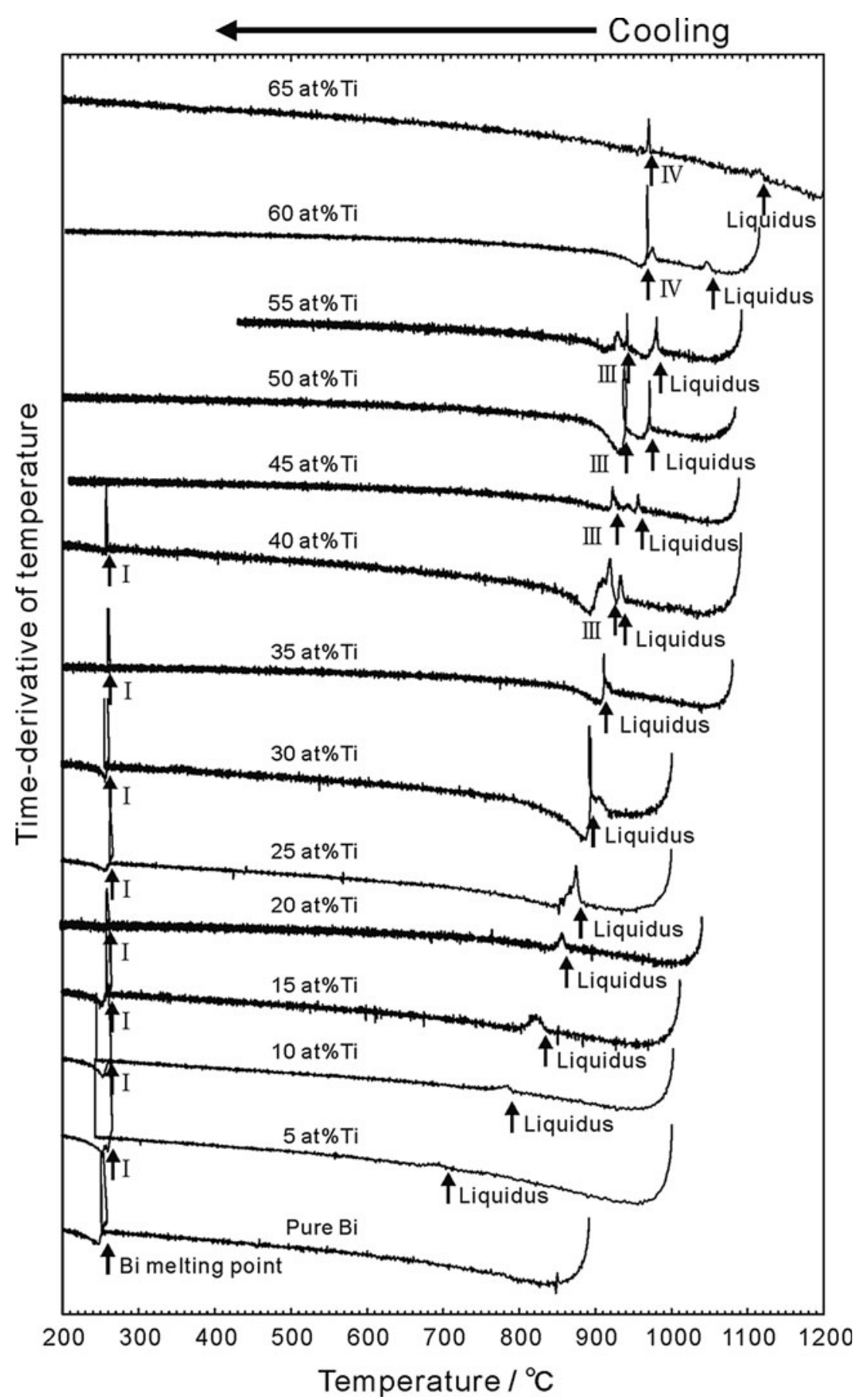

Fig. 3 Time derivative of temperature against temperature acquired by cooling curve measurements of the alloys containing 0-65 at.\% of Ti. The measurement of the alloy containing 55 at.\% of Ti was stopped at $400{ }^{\circ} \mathrm{C}$

than the cooling rate $\left(2^{\circ} \mathrm{C} / \mathrm{min}\right)$ at $500-400{ }^{\circ} \mathrm{C}$. It is considered that the cooling rate was too low to get a clear break on the curve. On the other hand, reaction III and the reaction at liquidus were not observed by the heating curve measurement. This is ascribed to a small amount of the intermetallic compounds and the low heating rate $\left(1^{\circ} \mathrm{C} / \mathrm{min}\right)$ above $900{ }^{\circ} \mathrm{C}$.

\subsection{Equilibrium Experiment}

In order to identify the invariant reactions II, III, and IV, equilibrium experiments were performed. Figure 6 shows the SEM images of the alloy containing 40 at. $\%$ of Ti held at $900{ }^{\circ} \mathrm{C}$ for $65 \mathrm{~h}$ (Exp. \#1). Seven different phases were observed and their compositions are shown in Table 2. The darkest phase $(\mathrm{G})$ in Fig. 6 is Ti phase. It 


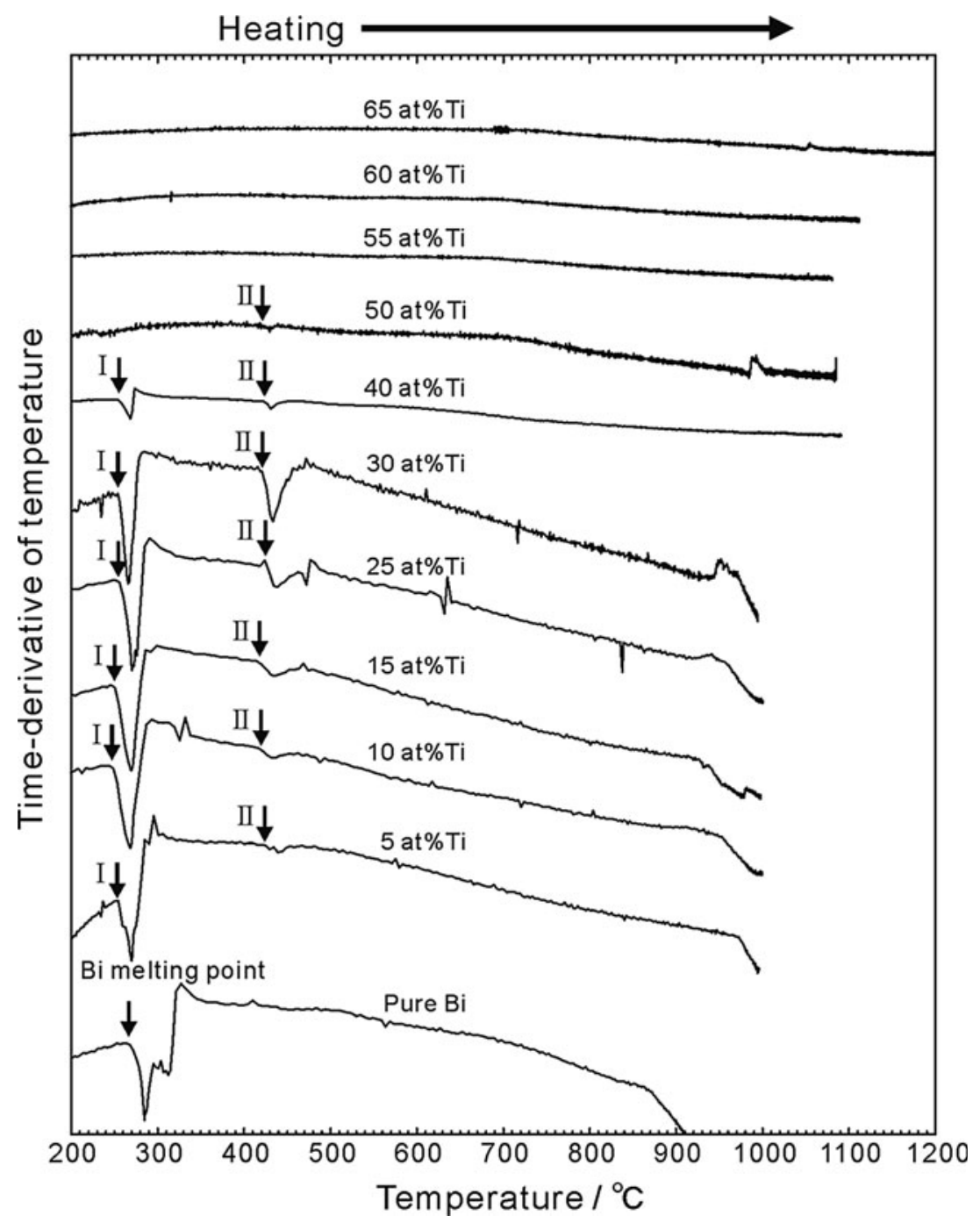

Fig. 4 Time derivative of temperature against temperature acquired by heating curve measurements of the alloys containing 0-65 at.\% of $\mathrm{Ti}$

is considered that undissolved $\mathrm{Ti}$ remained since the diffusion of $\mathrm{Ti}$ and $\mathrm{Bi}$ in the solid intermetallic compounds is kinetically limited. Around the $(\mathrm{G})$ phase, $\mathrm{BiTi}_{3}$ (F), $\mathrm{BiTi}_{2}$ (E), $\mathrm{Bi}_{2} \mathrm{Ti}_{3}$ (D), $\mathrm{Bi}_{9} \mathrm{Ti}_{8}(\mathrm{C})$, and liquid phase (A) were identified. Note that $\mathrm{Bi}_{2} \mathrm{Ti}_{3}$ is a new phase which has never been reported, and the reported $\mathrm{Bi}_{3} \mathrm{Ti}_{2}$ was not detected in this condition.

To make sure of the invariant reaction II, the alloys containing 30 at. \% of Ti held at 420 and $430{ }^{\circ} \mathrm{C}$ for $45 \mathrm{~h}$ (Exp. \#2, 3) were characterized by SEM-EDX (Fig. 7; Table 2) and XRD (Fig. 8). At $420^{\circ} \mathrm{C}$ (Exp. \#2), three phases, (A), (B), and (C), were observed. Phases (A) and (C) were the liquid phase and $\mathrm{Bi}_{9} \mathrm{Ti}_{8}$, respectively. Phase $(\mathrm{B})$ is probably $\mathrm{Bi}_{2} \mathrm{Ti}$ by the EDX results. The XRD pattern of $\mathrm{Bi}_{2} \mathrm{Ti}$ is not known, but some peaks corresponded to the pattern in the card of JCPDS \#00-051-1006, ${ }^{[9]}$ although there is no composition information about this card. At $430{ }^{\circ} \mathrm{C}$ (Exp. \#3), on the other hand, only liquid (A) and $\mathrm{Bi}_{9} \mathrm{Ti}_{8}$ (C) phases were identified by EDX, although the XRD pattern showed a small peak at $31^{\circ}$ due to $\mathrm{Bi}_{2} \mathrm{Ti}$. It is considered that a small amount of $\mathrm{Bi}_{2} \mathrm{Ti}$ was precipitated when the alloy was cooled during quenching in water. These results suggest that invariant reaction II is

$$
\mathrm{L}+\mathrm{Bi}_{9} \mathrm{Ti}_{8}=\mathrm{Bi}_{2} \mathrm{Ti}
$$




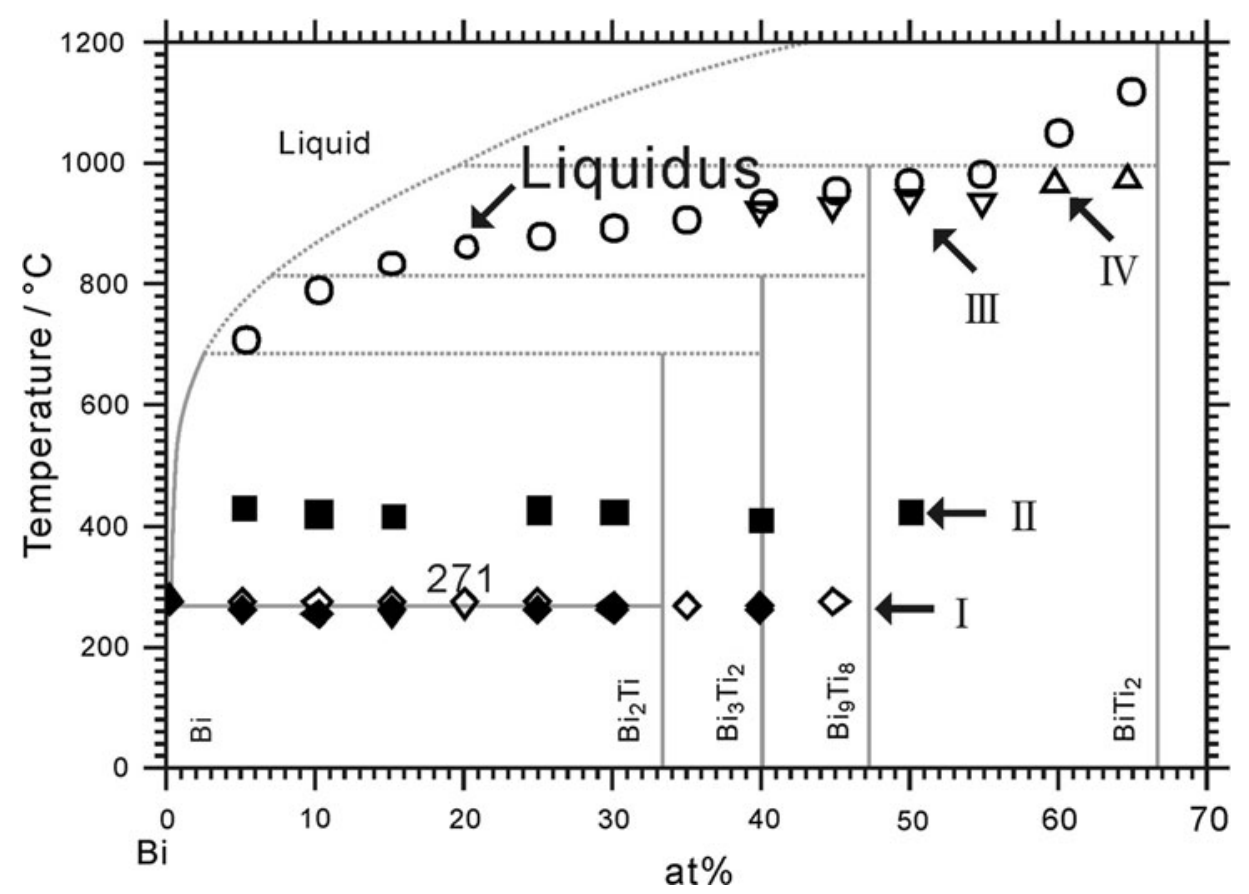

Fig. 5 Temperatures of the liquidus and invariant reactions obtained by cooling curves (blank) and heating curves (solid) on the reported phase diagram ${ }^{[7]}$

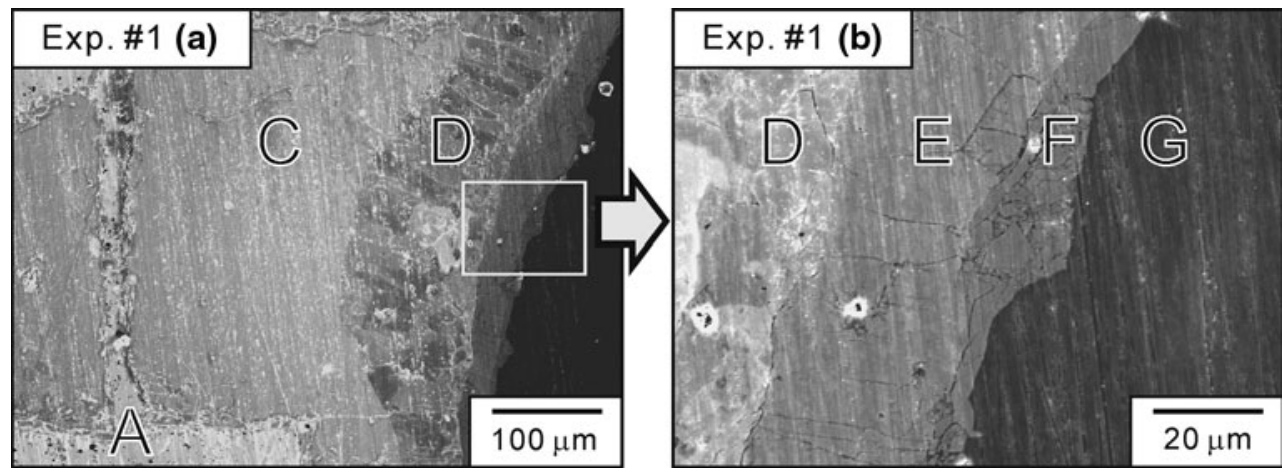

Fig. 6 SEM images of the alloy containing 40 at. $\%$ of Ti held at $900{ }^{\circ} \mathrm{C}$ for $65 \mathrm{~h}$ (Exp. \#1). (b) is a high magnification image of the marked area in (a)
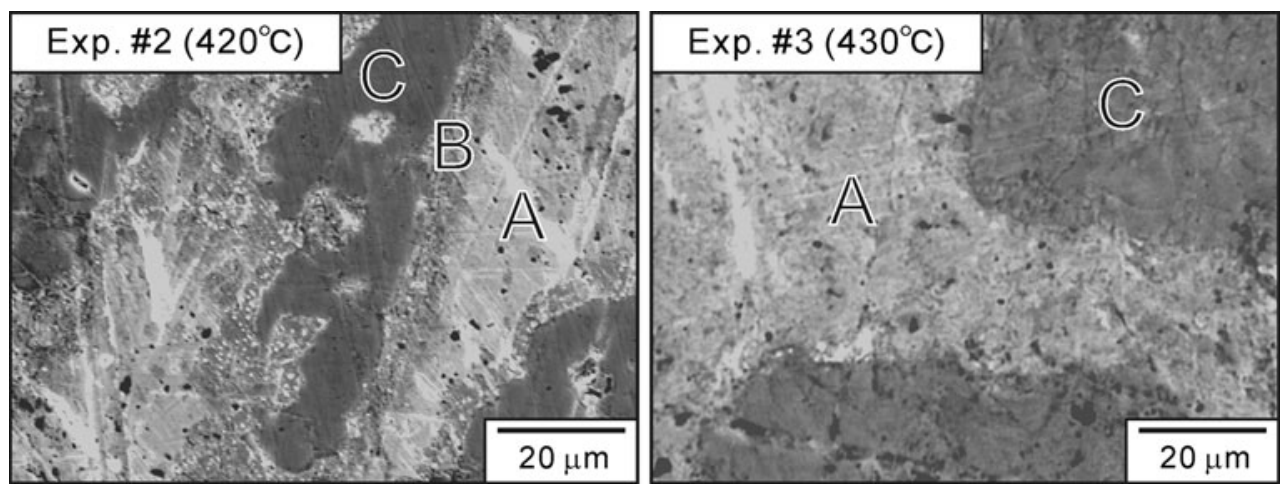

Fig. 7 SEM images of the alloys containing 30 at.\% of Ti held for $45 \mathrm{~h}$ at $420{ }^{\circ} \mathrm{C}$ (Exp. \#2) and at $430{ }^{\circ} \mathrm{C}$ (Exp. \#3) 


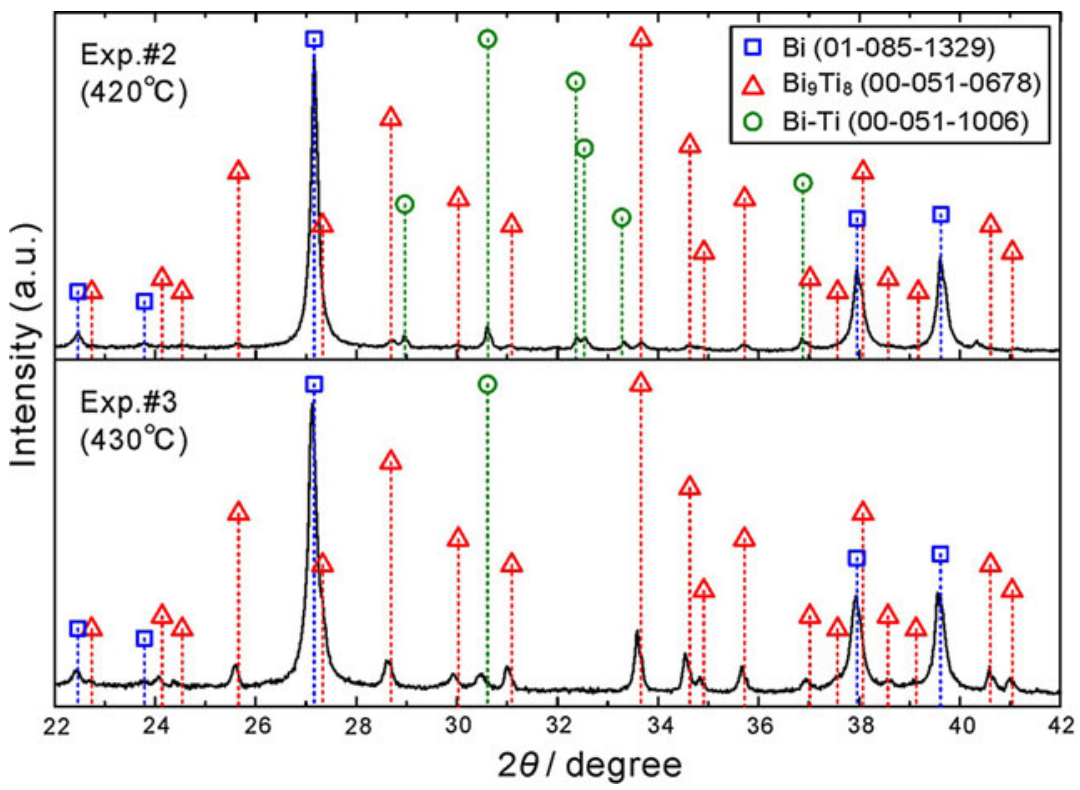

Fig. 8 XRD patterns of the alloys containing 30 at.\% of Ti held for $45 \mathrm{~h}$ at $420{ }^{\circ} \mathrm{C}\left(\right.$ Exp. \#2) and at $430{ }^{\circ} \mathrm{C}($ Exp. \#3)
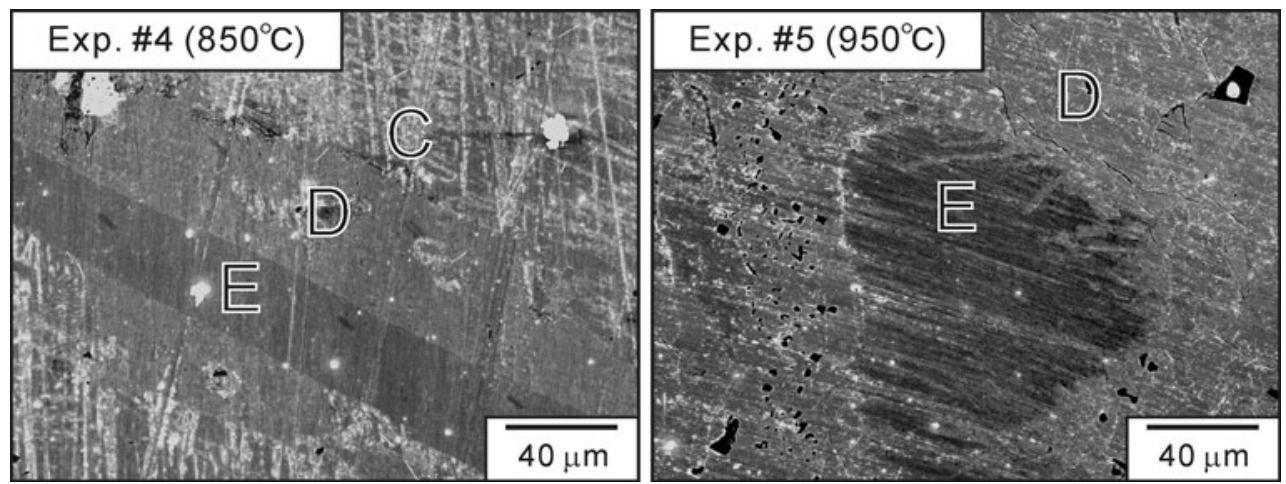

Fig. 9 SEM images of the alloys containing 50 at.\% of Ti held at $850{ }^{\circ} \mathrm{C}$ for $265 \mathrm{~h}$ (Exp. \#4) and 65 at. $\%$ of Ti held at $950{ }^{\circ} \mathrm{C}$ for $95 \mathrm{~h}($ Exp. \#5)

and its temperature is between 420 and $430{ }^{\circ} \mathrm{C}$. Here, $\mathrm{Bi}_{9} \mathrm{Ti}_{8}$ remained in the alloy of Exp. $\# 2\left(420^{\circ} \mathrm{C}\right)$ because of the slow formation of $\mathrm{Bi}_{2} \mathrm{Ti}$.

The SEM images of the alloys containing 50 and 65 at. $\%$ of Ti held at 850 and $950{ }^{\circ} \mathrm{C}$ (Exp. \#4, 5) are shown in Fig. 9 and the results of EDX are given in Table 2. $\mathrm{Bi}_{9} \mathrm{Ti}_{8}$ (C), $\mathrm{Bi}_{2} \mathrm{Ti}_{3}$ (D), and $\mathrm{BiTi}_{2}$ (E) were observed in Exp. \#4. $\mathrm{BiTi}_{2}$ remained because of the slow peritectic reaction $\left(\mathrm{L}+\mathrm{BiTi}_{2} \rightarrow \mathrm{Bi}_{2} \mathrm{Ti}_{3}\right)$. Considering this kinetic factor,
$\mathrm{Bi}_{2} \mathrm{Ti}_{3}$ and $\mathrm{Bi}_{9} \mathrm{Ti}_{8}$ are in equilibrium at $850{ }^{\circ} \mathrm{C}$. The result of Exp. \#5 indicates that $\mathrm{Bi}_{2} \mathrm{Ti}_{3}$ (D) and $\mathrm{BiTi}_{2}$ (E) were in equilibrium at $950{ }^{\circ} \mathrm{C}$. Thus, we conclude that invariant reaction III at $930{ }^{\circ} \mathrm{C}$ is

$$
\mathrm{L}+\mathrm{Bi}_{2} \mathrm{Ti}_{3}=\mathrm{Bi}_{9} \mathrm{Ti}_{8}
$$

and reaction $\mathrm{IV}$ at $970{ }^{\circ} \mathrm{C}$ is

$$
\mathrm{L}+\mathrm{BiTi}_{2}=\mathrm{Bi}_{2} \mathrm{Ti}_{3} .
$$




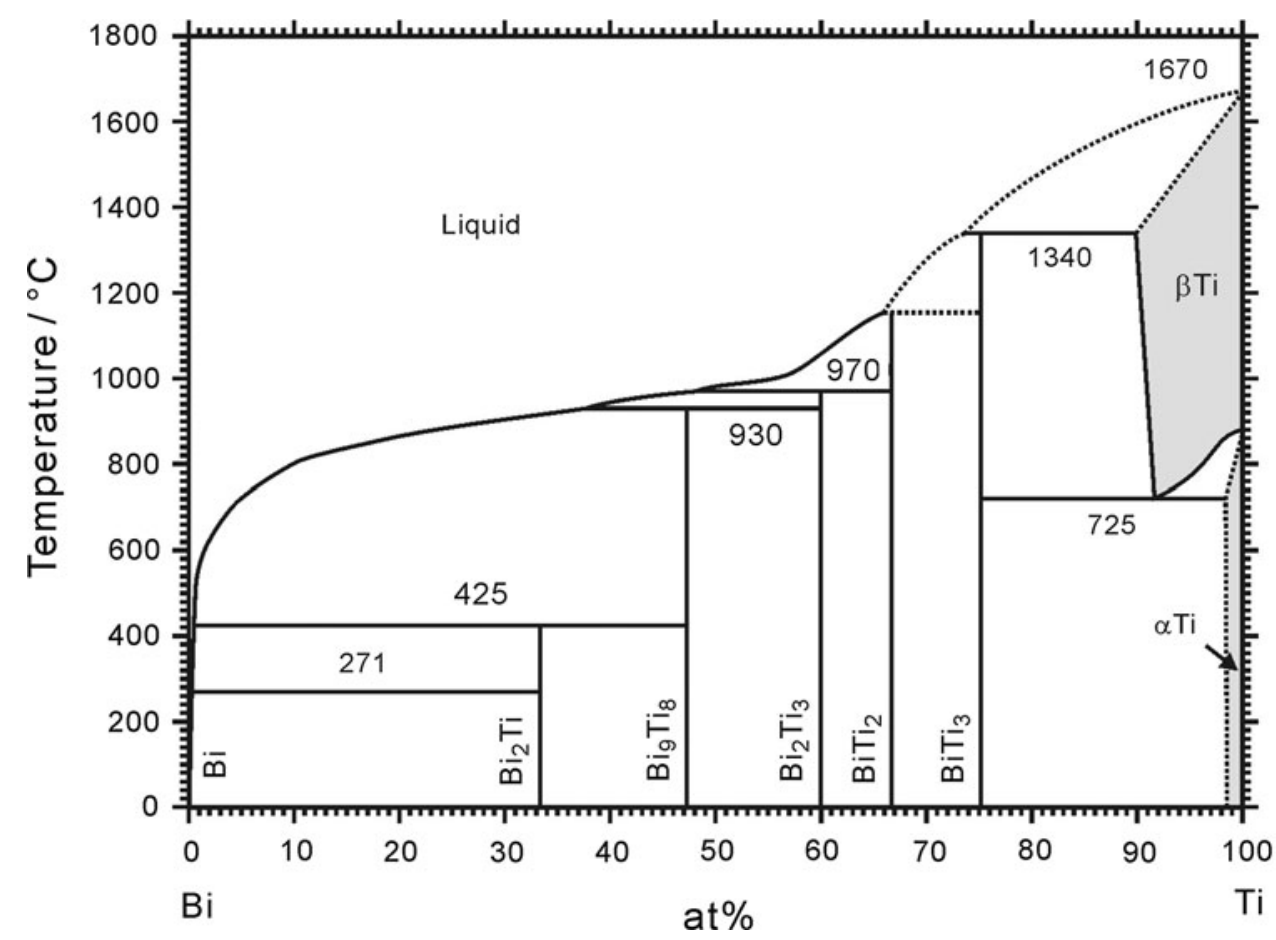

Fig. 10 The Bi-Ti phase diagram constructed by thermal analyses and equilibrium experiments

\section{Conclusions}

The Bi-Ti phase diagram was constructed by thermal analyses and equilibrium experiments as shown in Fig. 10. The liquidus temperature was significantly lower than the reported value. A new phase containing about 60 at. $\%$ of Ti $\left(\mathrm{Bi}_{2} \mathrm{Ti}_{3}\right)$ was found. No trace of $\mathrm{Bi}_{3} \mathrm{Ti}_{2}$ reported in the literature $^{[6]}$ was observed. It is possible that Vassilev ${ }^{[6]}$ regarded $\mathrm{Bi}_{3} \mathrm{Ti}_{2} \mathrm{O}_{x}$ as $\mathrm{Bi}_{3} \mathrm{Ti}_{2}$ since the quartz tubes were used as a container in his experiment.

\section{Acknowledgments}

This work was financially supported by the Advanced Low Carbon Technology Research and Development Program (Japan Science and Technology Agency). The authors would like to acknowledge Kamioka Mining \& Smelting Co. Ltd. for supplying the Bi metal. We would also like to express our deep thanks to Prof. Nose and Mr. Arisawa at Kyoto University.

\section{References}

1. J.L. Murray, The Bi-Ti (Bismuth-Titanium) System, Bull. Alloy Phase Diagr., 1994, 5, p 610-613

2. H. Auer-Welsbach, H. Nowotny, and A. Kohl, Untersuchung reibungspyrophorer Ti-Legierungen; Ti2Bi, ein neuer Strukturtyp, Monatsh. Chem., 1958, 89, p 154-159, in German

3. I. Obinata, Y. Takeuchi, and S. Saikawa, The System TitaniumBismuth, Trans. ASM, 1960, 52, p 1059-1071

4. T. Massalski, CD ROM: Binary Alloy Phase Diagrams, ASM International, Materials Park, OH, 1996

5. C.G. Richter and W. Jeitschko, Preparation and Crystal Structure of the Titanium and Hafnium Bismuthides $\mathrm{Ti}_{8} \mathrm{Bi}_{9}$ and $\mathrm{Hf}_{8} \mathrm{Bi}_{9}$, J. Solid State Chem., 1997, 134, p 26-30

6. G.P. Vassilev, Contribution to the Ti-Bi Phase Diagram, Cryst. Res. Technol., 2006, 41, p 349-357

7. H. Okamoto, Bi-Ti (Bismuth-Titanium), J. Phase Equilib. Diffus., 2010, 31, p 314-315

8. J.R. Weeks, Liquidus Curve of 19 Dilute Binary Alloys of Bismuth, Trans. ASM, 1965, 58, p 302-322

9. V. Simic and Z. Marinkovic, Reactions in Thin Ti/Metal Couples During R. F. Sputtering, Thin Solid Films, 1990, 191, p 165-171 